\title{
Annual and Seasonal Shoreline Evolution of Tainan Gold Coast Using Multiband Satellite Images
}

\author{
Hsien-Kuo Chang, Wei-Wei Chen, Feng-Chun Tsai, Jing-Chen Liou, and Shao-Gu Kuo
}

\begin{abstract}
The beach of Tainan Gold Coast (TGC) has been suffering from beach erosion for the past decades. Few bathymetrical measurements are available to accurately estimate the annual and seasonal shoreline changes. Alternatively, the NDWI-based algorithm is used to extract the waterline of a satellite image and the shifting correction of a waterline to the shoreline due to tidal effect is proposed in the paper. The proposed method was examined to be valid for engineering application from a comparison with slight difference between two obtained shorelines and measured in-site shorelines for 2004 and 2006.

Annual and seasonal rates of shoreline changes are estimated by the proposed method for TGC. The shoreline of the northern TGC moves onshore in the summer and oppositely offshore in the winter. The ratio per year at the southern beach of TGC is assessed to show severe erosion. The proposed method is applicable for studying the shoreline change.
\end{abstract}

Index Terms-Shoreline change, image fusion, multispectral image, seasonal variation.

\section{INTRODUCTION}

The beach of Tainan Gold Coast provides visitors with various luxury activities, such as playing a kite, sunset watching, and beach strolling. However, the TGC beach has been suffering from beach erosion for the past decades. Ministry of Economic Affairs (MEA) and the government of Tainan City engaged engineers to propose some good advices in coastal coutermeasurements about the beach erosion in different periods. The problem of beach erosion is still suspended now. A common way to solve the problem is to accurately estimate the seasonal beach erosion and nearshore sediment transports using bathymetrical measurements over a long period of time at first. Based on analysis on the beach bathymetry some suitable treatments of shore protection are suggested by coastal engineers and then decided to a finalized project using multi-function assessment. Bathymetrical data are the key for solving the problem of beach erosion.

The morphological changes resulted from tides, ocean waves or nearhore currents in a coast can be analyzed by some approaches. Shoreline change is an easier approach to

Manuscript received October 21, 2016; revised May 21, 2017. This work was supported in part by the Ministry of Science and Technology, Taiwan under Grant No. NSC100-2221-E009-005.

H. K. Chang, W. W. Chen, F. C. Tsai, and J. C. Liou are with the Department of Civil Engineering, National Chiao-Tung University, Hsinchu 300, Taiwan (e-mail: hkc@mail.nctu.edu.tw, steve.cv90g@nctu.edu.tw, frank0451250.cv04g@g2.nctu.edu.tw, jcliou.cv87g@nctu.edu.tw).

Shao-Gu Kuo is with Harbor and Coastal Engineering Department, CECI Engineering Consultants, Inc., Taipei 11491, Taiwan (e-mail: bruce@ceci.com.tw). visually represent beach evolution than bathymetrical variation under the sea. Location of the shoreline and its rate of shoreline change can provide valuable information for the planning and design of coastal protection works and for the calibration and verification of numerical models.

Field measurements to obtain shoreline records in different times need sufficient funds so that such data are not easy to be available in actual cases. An alternative way is to use the waterline extracted from a satellite image. The waterline is one type of shoreline indicator, defined as a wet/dry line on the beach, which is used to describe the land-water boundary at the instant of image processing [1]-[5]. For coastal engineering the waterline at mean sea level (MSL) is commonly defined as the shoreline. Pardo-Pascual et al. [6] indicated that the applicability of the waterline extraction method in areas with high tidal ranges is an important issue in tidal flats. Ryu et al. [7] noted that the waterline is also an important factor to be considered on the middle tidal flat.

For a calm sea, ocean tides represent the rhythmic rise and fall of the sea level with time. These tides are manifested at a coastline by the periodic advancing and receding of the waters over the shore. Thus, the extracted waterlines from different satellite images taken over the same place over a short period can be in various positions depending on the different tidal elevations at the time each satellite image was taken. Boak and Turner [8] proposed that the use of the instantaneous waterline seems misguided because it represents the position of the land/water interface at one instant in time rather than "normal" or "average" conditions. Considering these tidal variations for different satellite images, Chen and Chang [9] proposed the one-line shift method, which shifts the extracted waterlines on three sequential satellite images to the corresponding shorelines at MSL when the foreshore beach slope is unknown. Other minor correction on the shoreline position from a waterline is the effect of wave's runup. Chang et al. [10] proposed applicable methods to shift the waterline on each satellite image for available/unavailable the beachface slope of each section.

Waterline extraction from satellite images and shoreline correction are applied to investigating annual and seasonal beach changes of TGC, Taiwan in the paper. Section 2 states the location of TGC and data collection. Key skills of image processes are introduced in section 3, involving: (1) fusing multispectral image information for promoting the spatial resolution; (2) determining the NDWI-based waterline associated with supervised classification and (3) shifting shoreline by the tidal correction. Results and discussion on the annual and seasonal beach changes of TGC are presented in section 4. Final section indicates the conclusion of this study. 


\section{BACKGROUND AND DATA}

The location of TGC with the beach of $5 \mathrm{~km}$ long between the Anping harbor and the Erren river at Tainan is shown in Fig. 1.

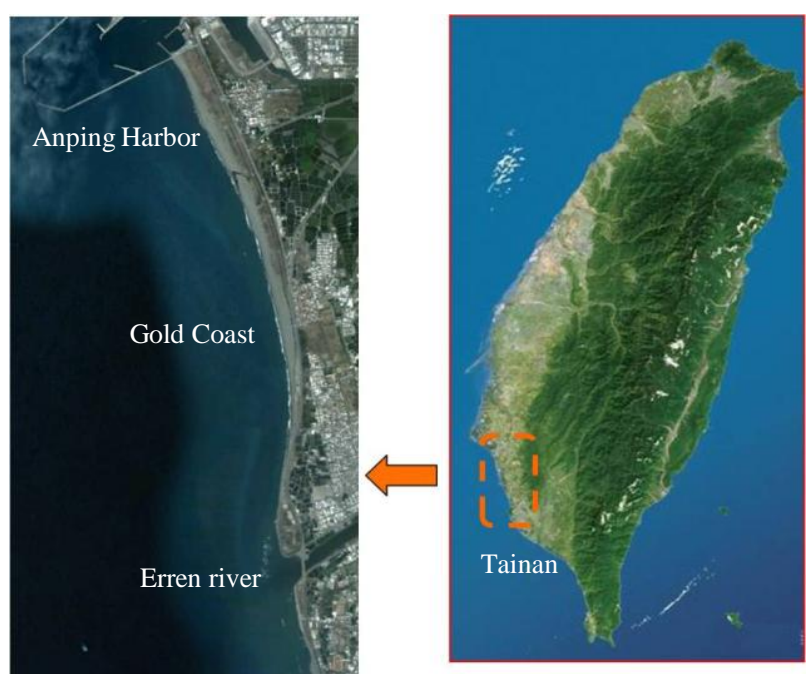

Fig. 1. Location of Tainan Cold Coast and the Anping Harbor.

High spatial resolution of SPOT5 and FORMOSAT-2 images is considered for accurate boundary detection. Both spatial resolutions of panchromatic images are $2.5 \mathrm{~m}$ and 2.0 $\mathrm{m}$, respectively. However, the spatial resolutions of the corresponding multispectral images are generally quadruple to those of panchromatic images. Nineteen satellite images were collected from 2004 to 2010 in this study.

Wave data were measured by the Institute of Harbor and Marine Technology (IHMT), as an affiliate to the department of transportation of the Taiwan provincial government, with the Nortek AWAC mounted at offshore observation pole away from the Tainan Harbor, where the depth is about $15 \mathrm{~m}$, from 1999 to 2015. AWAC is well suited for real-time ocean observing systems when integrated with the NIP processor and Nortek underwater acoustic modems. The monthly averaged heights and periods of significant waves over 16 years are obtained by IHMT and shown in Fig. 2. Fig. 2 shows that the waves in the summer are slightly higher and longer than those in the winter. Most winter waves mainly come from WNW and most summer waves are in SW.

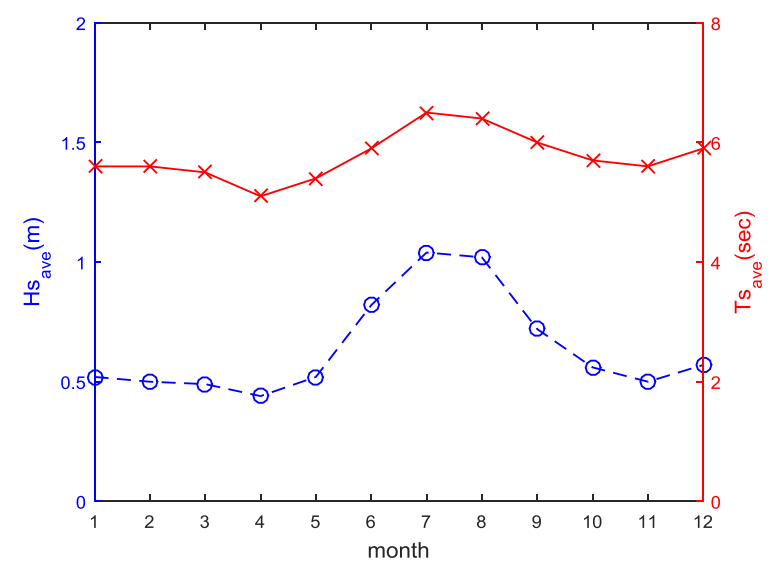

Fig. 2. Monthly averaged heights and periods of hourly significant waves at the Tainan Harbor from 1999 to 2015.
Maximum and mean wind velocities over the first ten minute per hour are monthly averaged from 2009 to 2015 and the results are shown in Fig. 3. It is seen from Fig. 3 that the mean wind velocity of each month is undistinguished but averaged maximum wind velocities from June to September are much higher than those in other months.

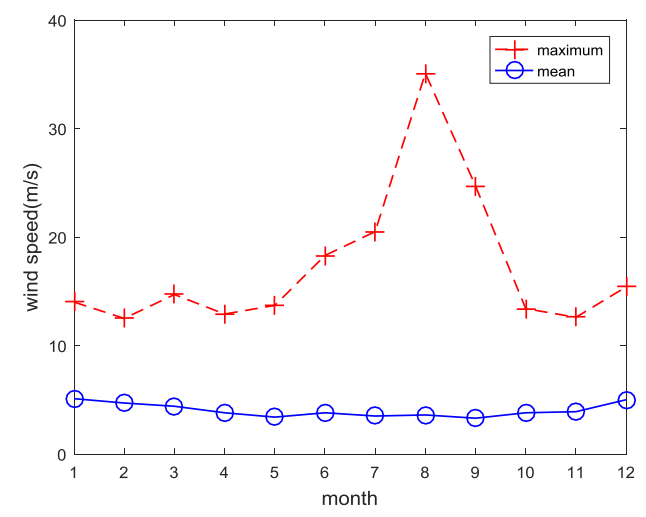

Fig. 3. Maximum and mean hourly wind velocities at the Tainan Harbor monthly averaged from 2009 to 2015.

Statistical analysis on tidal data of the Central Weather Bureau (CWB) in Taiwan from 2001 to 2010 was done to have the monthly averaged MSL, high/low water on spring tide (HWOST and LWOST) and mean high/low water line (MHWL and MLWL) as shown in Fig. 4. Fig. 4 shows that the averaged MSL, MHWL and MLWL are in convex curves with a peak in August and their mean tidal ranges of about $0.64 \mathrm{~m}$. Both HWOST and LWOST vary of about $0.4 \mathrm{~m}$ and their extremes occur in July and in June.

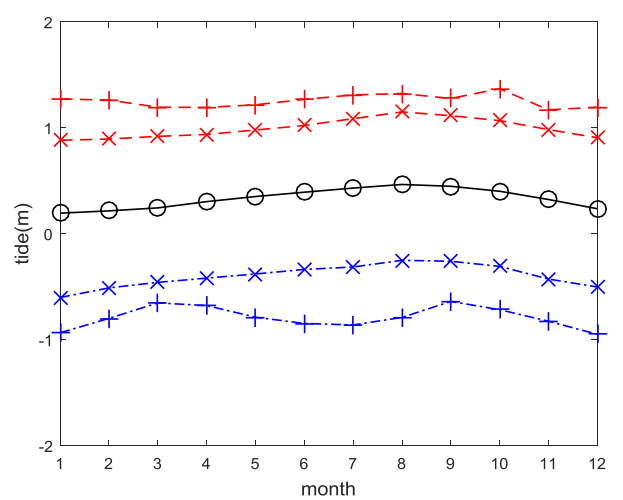

Fig. 4. Monthly averaged MSL, HWOST/LWOST and MHWL/MLWL from 2000 , denoted by $\bigcirc,+$ and $\times$, respectively.

The shoreface slope of southern and northern parts of TGC are about $1 / 30$ and $1 / 24$, respectively, from the bathymetrical measurement in May, 2006. The mean diameters of sands on the southern and northern beaches of TGC are $0.206 \mathrm{~mm}$ and $0.246 \mathrm{~mm}$ in the summer, and $0.195 \mathrm{~mm}$ and $0.216 \mathrm{~mm}$ in the winter, respectively.

\section{METHODS}

The materials in this paper include satellite-derived data, oceanic conditions, and beach features. IHS image fusion to 
promote the resolution of image information is introduced at first. Then the waterline in an image is determined by an index of NDWI associated with supervised classification. Based on beach features the shifting waterline to shoreline was proposed in the third sub-section.

\section{A. IHS-Based Image Fusion}

Information of a multispectral image will be used to compute an index for determining waterlines. However, the spatial resolution of multispectral images is low. Therefore, image fusion of spatial resolution of multispectral images is required in the image process in this study.

IHS is one of the widely used image fusion methods in the remote sensing studies and has been well developed as a standard procedure in some commercial packages. IHS transform converts a multispectral image or panchromatic image with red, green and blue channels (RGB) to intensity, hue and saturation, three independent components (IHS).

The conversion of IHS from RGB of image information identifies the pixels located on the surface of a saturation cone with saturation values proportional to distinct intensities. The IHS-based fusion is to replace the intensity of a pan image instead of those of low-resolution images.

An original image and its fused image are shown in Fig. 5. The fused image shows a finer and brighter picture than the original one.

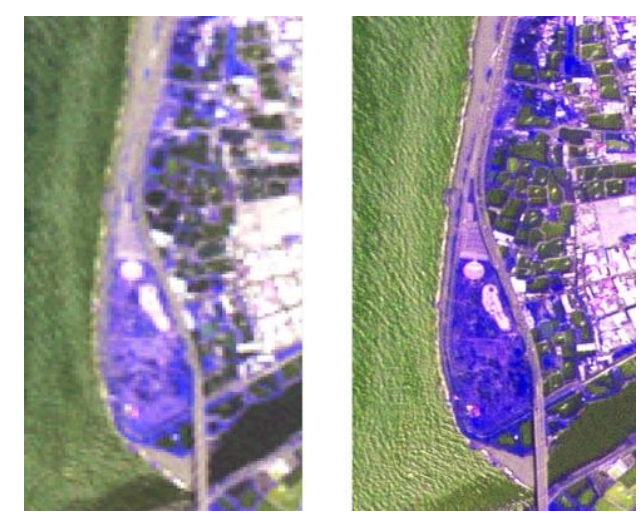

Fig. 5. Resolution demonstration of an original image and its fused image.

\section{B. Zero NDWI}

The normalized difference vegetation index (NDVI) has been widely used for remote sensing of vegetation for many years [11]-[20]. Water body absorbs solar radiation and its reflectivity is relatively weak. The most important issue of extracting water body information is to eliminate the noises resulted from the shadows having the similar spectral characteristic with water body. Following the simplicity of NDVI, Mcfeeters [21] and Gao [22] proposed a normalized difference water index, NDWI, to evaluate vegetation and liquid water in remote sensing.

NDWI is defined by the ratio of individual measurements as follows

$$
N D W I=\frac{N I R-G}{N I R+G}
$$

where $G$ and NIR stand for the spectral reflectance measurements acquired in the visible green bands with a range of $0.52 \mu \mathrm{m}-0.60 \mu \mathrm{m}$ and near-infrared bands with a range of $0.79 \mu \mathrm{m}-0.89 \mu \mathrm{m}$, respectively. Instead of the green bands in Eq. (1) NDVI uses the red bands. Fig. 6 shows the positions of zero NDVI and NDWI of a chosen profile A-B, taken as an example for the reflectivity of the green band, the red band and the near-infrared band. The result indicates that the position of zero NDVI, L2, is different from that of zero NDWI, L1.
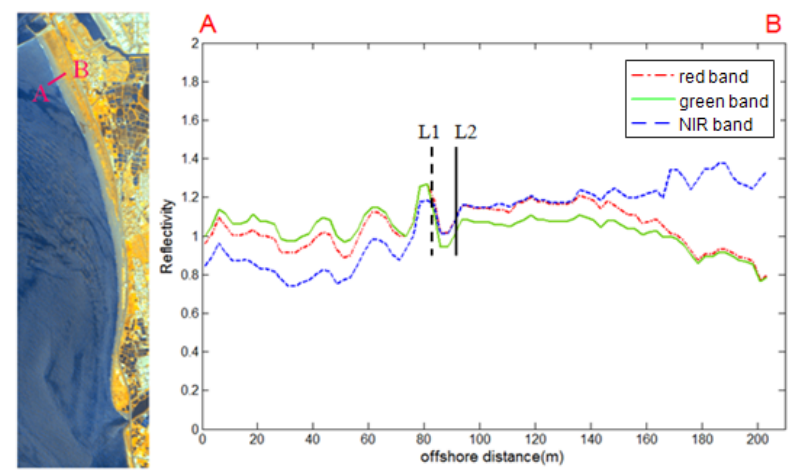

Fig. 6. Location of zero NDVI and NDWI at the chosen profile A-B of the image on $30^{\text {th }}$ March, 2006.

Fig. 7 indicates the positions of zero NDVI and NDWI at the southern TGC. The positions of zero NDVI are more rugged than those of zero NDWI. Therefore, it is easy and suitable to extract the possible waterline by the positions of zero NDWI, which are close to real waterline.

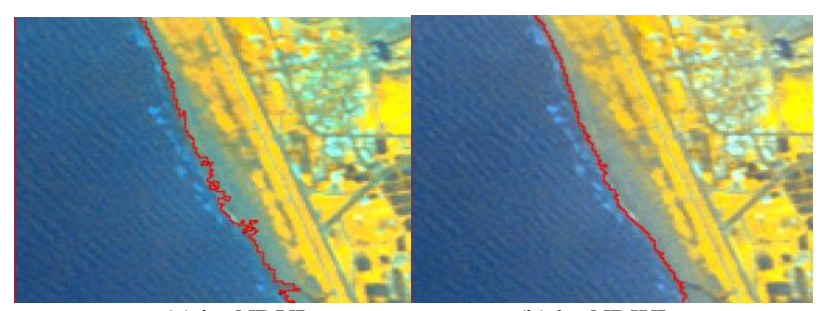

(a) by NDVI

(b) by NDWI

Fig. 7. Positions of zero NDVI and NDWI at the southern TGC.

\section{Supervised Classification for Waterline Extraction}

In order to accurately determine the waterline from an image, the supervised classification is used for correct waterline extraction. Different land features are represented by digital image classification techniques group pixels for engineering applications. Unsupervised image classification, supervised image classification and object-based image analysis are three kinds of image classification techniques. Supervised image classification is suitable for determing the waterline which is simple to separate the sea (water) from the beach (land).

The machine learning task of inferring a function from a set of labeled training data is executed on supervised classification. In supervised learning, each example is a pair consisting of input objects and desired output values. A supervised learning algorithm analyzes the training data and produces an inferred function, which can be used for mapping new examples. A well learned model is requested to correctly determine the class labels for unlearned instances. This 
requires the learning algorithm to generalize from the training data to unseen situations in a "reasonable" way.

Maximum likelihood supervised classifier (MLC) is a commonly used algorithm for supervised classification. MLC is performed according to the following steps [23]:

(1) Display the three-band overlay composite image. The visible channels are associated with red, green and blue, respectively so that the clouds look white, vegetation looks green, water looks dark and lands without vegetation looks different shades of brown. Determine two classifications in the image to be segmented.

(2) Choose 10 representative training samples for each of the desired classes from the color composite image, shown as Fig. 8. These pixels are said to form training data. The samples on the sea are denoted by yellow-colored areas and those on land are shown by red-colored areas.

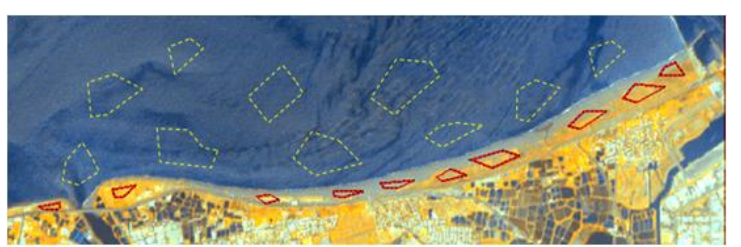

Fig. 8. Chosen representative training samples for water and land groups.

(3) Use the training samples to estimate the mean vectors and covariance matrixes for MLC classifier.

(4) Use the trained classifier to classify every pixel in the image into one of two desired classes shown in Fig. 9.

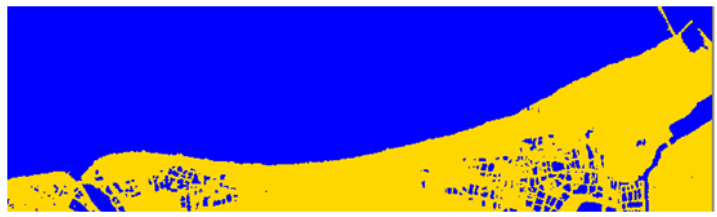

Fig. 9. Two desired classes separated by MLC.

The boundary between two separated classes in Fig. 9 is assumed to be the waterline which is defined to be the position of intersection between water and land on the beach. The detected waterline of TGC by MLC from the satellite image on March 3rd, 2006 is shown in a red line of Fig. 10.

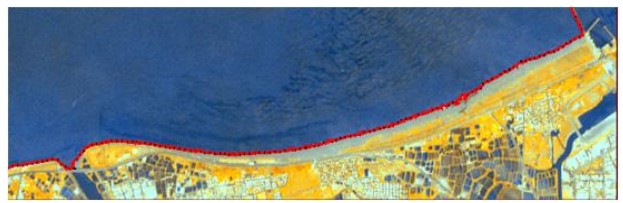

Fig. 10. Detected red-colored waterline of TGC by MLC from the satellite image on March 3, 2006.

In order to evaluate the accuracy of detected waterlines from the above satellite image, both NDVI-based and NDWI-based waterlines are compared with the measured in-site shoreline during May 2006. The result is shown in Fig. 11. It is seen in Fig. 11 that two detected waterlines have a bias against the measured shoreline and the NDVI-based waterline is more rugged and deviates more from the measured shoreline towards the land than the NDWI-based waterline. The deviation of waterline from the shoreline results from the tidal level at the shooting time of the satellite image is above MSL by $0.284 \mathrm{~m}$. Therefore, the waterline lies landwards above MSL.

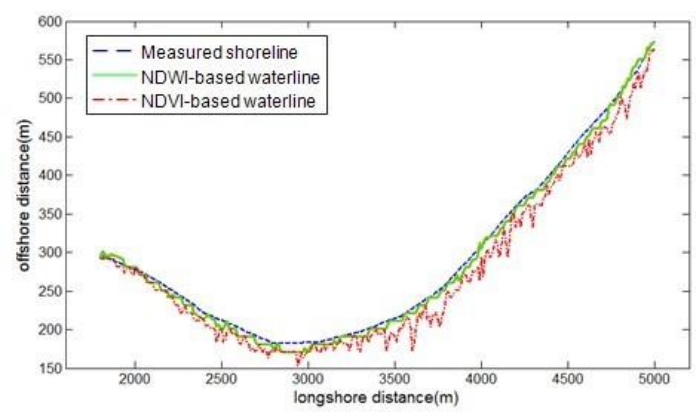

Fig. 11. NDVI-based and NDWI-based waterlines and measured in-site shoreline for May, 2006.

\section{Shifting Waterline to Shoreline}

Due to non-zero tidal level, the waterline should be horizontally shifted to MSL. If both tidal level and beach slope are known, the shifted horizontal distance from waterline to shoreline equals the tidal level divided by the beach slope through the triangular geometry.

\section{RESUlTS AND DisCUSSION}

\section{A. Evaluation of Model Accuracy}

Root mean squared error (RMSE) and bias are common indexes for evaluating model performance. Both indexes are defined, respectively, as

$$
\begin{aligned}
& \text { RMSE }=\sqrt{\sum_{i=1}^{N}\left[y_{c}\left(x_{i}\right)-y_{m}\left(x_{i}\right)\right]^{2} / N} \\
& \text { bias }=\frac{1}{N} \sum_{i=1}^{N}\left[y_{c}\left(x_{i}\right)-y_{m}\left(x_{i}\right)\right]
\end{aligned}
$$

where $y_{m}$ and $y_{c}$ are the measured and computed shorelines at $x_{i}$ and $N$ is the number of chosen sections. Small RMSE is expected to show little deviation of the detected shoreline from the measured shoreline. Negative bias indicates that the detected shoreline generally lies landwards above the measured shoreline. Otherwise positive bias shows the detected shoreline lies seawards below the measured shoreline.

The NDWI-based waterline of Fig. 11 has a RMSE of 6.65 $\mathrm{m}$ and a bias of $-4.67 \mathrm{~m}$. However, RMSE of the NDVI-based waterline for the case is $19.42 \mathrm{~m}$ and a bias is $-16.60 \mathrm{~m}$. The averaged beach slope on TGC is about $1 / 30$. Thus averaged shifting of waterline to shoreline for the case is estimated to be seaward by $0.28 \times 30=8.40 \mathrm{~m}$. If the NDWI-based waterline is shifted by a distance of $8.4 \mathrm{~m}$, the shifted waterline can be estimated to have a bias from the measured shoreline by about $8.40-4.67=3.73 \mathrm{~m}$. Following the estimation, the shifted NDVI-based waterline has a bias from the measured shoreline is about $-8.2 \mathrm{~m}$. Smaller RMSE and bias of shifted NDWI-based waterline than those of shifted NDVI-based waterline indicates that the NDWI-based shoreline by the proposed method is more valid for accurately estimating shoreline change than the NDVI-based shoreline. 
Two in-site bathymetrical measurements on TGC were carried out in September 2004 and in May 2006. The measured shorelines can be taken as a baseline to compare with the determined shorelines of two images, of which the shooting times are on September 4th, 2004 and March third, 2006, close to the corresponding measurement date.

The detected waterline and shifted shoreline are compared with its corresponding measured shoreline by Eq. (2) and Eq. (3). Both RMSE and bias are listed in Table I for these two cases.

TABLE I: RMSE AND BIAS BETWEEN THE MEASURED SHORELINES AND DETECTED WATERLINES/SHORELINES FROM TWO IMAGES

\begin{tabular}{ccccc}
\multicolumn{2}{c}{ DETECTED WATERLINES/SHORELINES FROM TWO IMAGES } \\
\hline \hline \multirow{2}{*}{ Index } & \multicolumn{2}{c}{ 2004/09/04 } & \multicolumn{2}{c}{ 2006/03/30 } \\
\cline { 2 - 5 } & waterline & shoreline & waterline & shoreline \\
\hline \hline RMSE $(\mathrm{m})$ & 7.40 & 6.81 & 6.65 & 5.51 \\
\hline \hline bias $(\mathrm{m})$ & 4.04 & 2.84 & -4.67 & 2.69 \\
\hline \hline
\end{tabular}

That the waterlines deviate more from the measured shorelines by a larger RMSE and bias than the shifted shorelines is expectable for tidal effect. The tidal variation in Tainan waters is small so that the shifting correction is insignificant. The result indicates that the estimated beach slope can be applicable for real beach slope.

The spatial resolution of all chosen panchromatic images is about $2.5 \mathrm{~m}$. The obtained NDWI-based waterline is from fused multispectral images, of which the spatial resolution is similar to that of panchromatic image. The values of bias for two cases being $-0.26 \mathrm{~m}$ and $3.36 \mathrm{~m}$ seem close to the spatial resolution of a fused image and are reasonably expected. Based on the above model evaluation, the shifted shorelines by the proposed method are examined valid for the coming discussion on annual and seasonal shoreline variations.

\section{B. Annual Rate of Shoreline Change}

Shoreline variation at a section is oriented to be normal to the beach instead of the E-N directions. In order to determine the normal direction of the TGC we plot the mean shoreline, obtained by time averaging over all shifted shorelines from satellite images at the same $\mathrm{x}$ in Fig. 12. Two shifted shorelines for 2004 and 2010, which is the beginning and the end of collected image time were also illustrated in Fig. 12. It is seen that the mean TGC shoreline shows a concave contour and lies between two chosen shorelines. The gradient of the positions $(\mathrm{x}, \mathrm{y})$ of the mean shoreline indicates the normal to the beach.

We choose six sections denoted $\mathrm{A}$ to $\mathrm{F}$ in Fig. 12 to demonstrate their shoreline variations. The annual rate of shoreline change at each section is estimated by linearly fitting for all obtained data which are separated into parts of summer and winter and denoted by crosses and open circles, respectively in Fig. 13. According to beach change rates and monthly averaged maximum wind velocity the summer shoreline is defined as the period during June to September and the winter shoreline is in other months. In Fig. 13 a solid curve indicates the timely smoothed positions of shoreline at different time and the dashed curve denotes its corresponding slope. Fitted lines of Fig. 13 (a) to (c) are inclined from steeply to mildly with a value of $-15.61,-7.51$ and -5.50 $\mathrm{m} /$ year, respectively. The results show that these sections have been suffering from beach erosion for the period of 2004 to 2010 . The fitted line with a slope of $0.0014 \mathrm{~m} /$ year in Fig. 13 (d) displays almost horizontal to indicate that the annual rate of the section $\mathrm{D}$ is invariant over a long time. The sections $\mathrm{E}$ and $\mathrm{F}$ indicate an increasing fitted line of Fig. 13 (e) and (f) with equivalent slopes of 2.61 and $2.88 \mathrm{~m} /$ year, respectively.

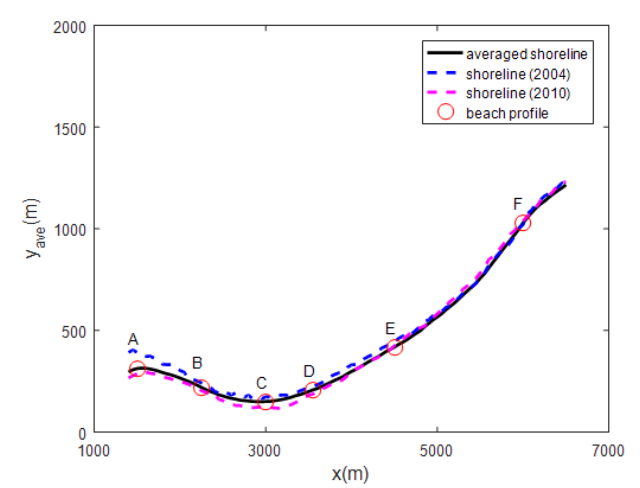

Fig. 12. Mean shoreline of all obtained shorelines and chosen six positions.

Following the above step of obtaining the slope of fitted lines of Fig. 13 we compute the annual rate of shoreline change at all sections with an equal space of $\mathrm{x}=50 \mathrm{~m}$ along TGC. The result is shown in Fig. 14. The annual rates almost approach zero from $\mathrm{x}=3500$ to $4400 \mathrm{~m}$. Annual erosion at the southern end is most severe and gradually slow down up to $\mathrm{x}=3000 \mathrm{~m}$. Northern beaches have a bell-shaped annual rate of shoreline change with a wide band and a peak of 6.79 $\mathrm{m} /$ year at $\mathrm{x}=5300 \mathrm{~m}$. We can take the mean of annual rates of shoreline change over the range of $x=4400-6500 \mathrm{~m}$ to be $3.94 \mathrm{~m} /$ year to have the average rate for northern beaches. The area of negative erosion rate along TGC being larger than that of accretion rate is shown in Fig. 14.

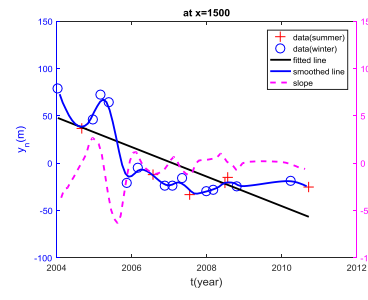

(a) Location $\mathrm{A}$

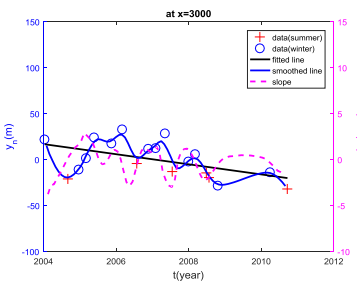

(c) Location $\mathrm{C}$

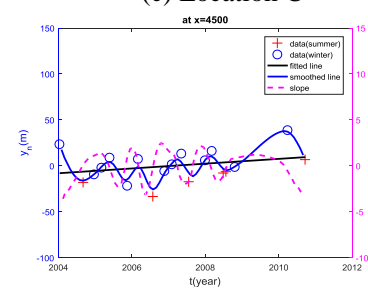

(e) Location E

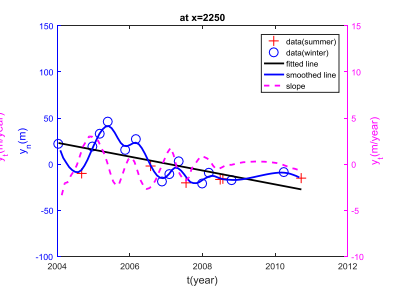

(b) Location B

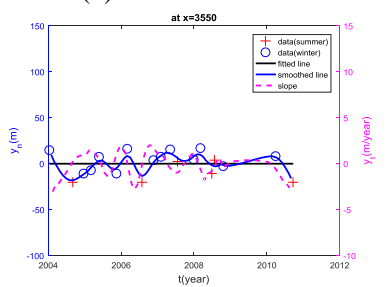

(d) Location D

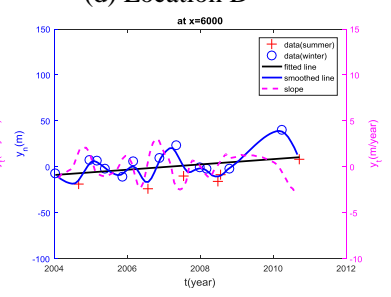

(f) Location F
Fig. 13. All shifted shorelines at six positions, their fitted lines, smoothed curves and the corresponding slopes. 


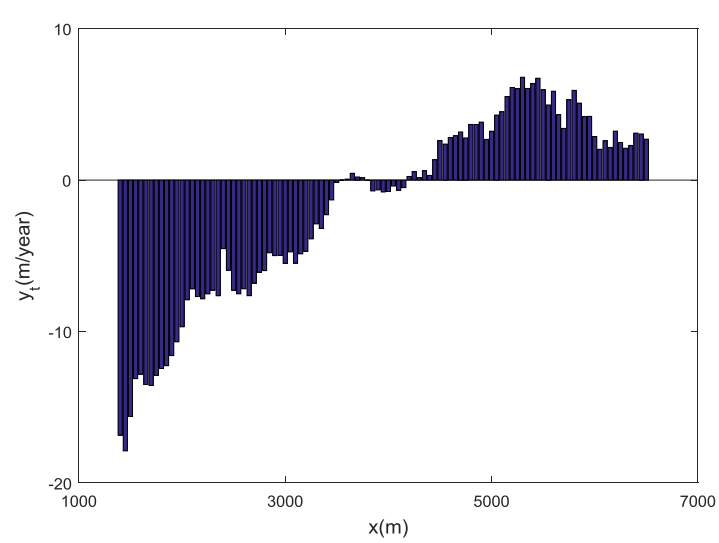

Fig. 14. Annual rate of shoreline change along TGC.

Integrating the positions of shoreline with respect to $x$ yields mean offshore distance of each shoreline along TGC. All mean offshore distances and their fitted line are shown in Fig. 15. It is clearly seen that the fitted line is declined by a negative slope of $-1.53 \mathrm{~m} /$ year and the distances in the summer are at local extremals low the fitted line. The result indicates that the whole beach of TGC is gradually eroded and the occurrence time of beach erosion is in summer.

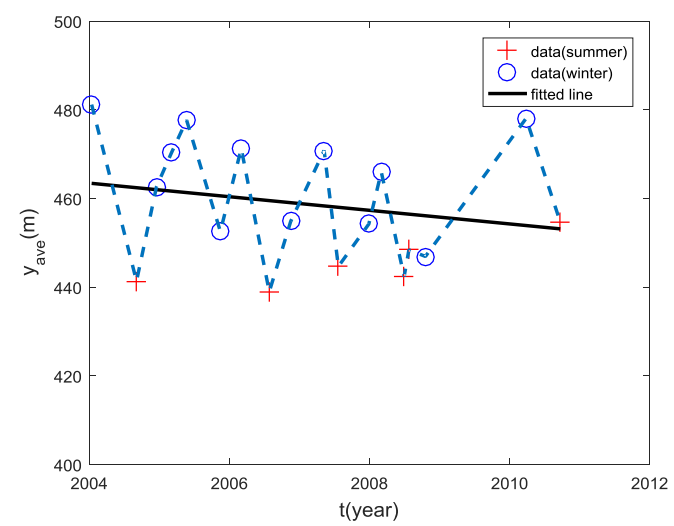

Fig. 15. Annual rate of averaged shoreline along TGC.

\section{Seasonal Rate of Shoreline Change}

From Fig. 13 (c) to Fig. 13 (f) and Fig. 15 it is obviously seen that the last open circle of each year directs downwards to a next cross, indicating a negative slope, and a cross rises to a next open circle, showing a positive slope. The resulting slopes imply that the winter beach of each year is accumulated to move landwards but the summer beach of each year moves seawards by erosion. Beach changes at six positions show the regular seasonal variation. However, the summer and winter beaches for Fig. 13 (a) and (b) don't follow the rule. In order to illustrate the seasonal rate of shoreline change from summer to winter each year, the values of four extremal peaks in $y_{t}$ of Fig. 13 are shown in error bars with a mean by open circles from $\mathrm{x}=3000 \mathrm{~m}$ to $6500 \mathrm{~m}$ in Fig. 16. Rates of shoreline change of all sections from summer to winter are positive to have beach accretion. Mean of these accretion rates of each section varies from 1.02 to $2.82 \mathrm{~m} /$ year with a standard deviation $0.468 \mathrm{~m} /$ year. Averaging all means and standard deviations of all sections leads to be 1.86 and 0.692 $\mathrm{m} /$ year, respectively.

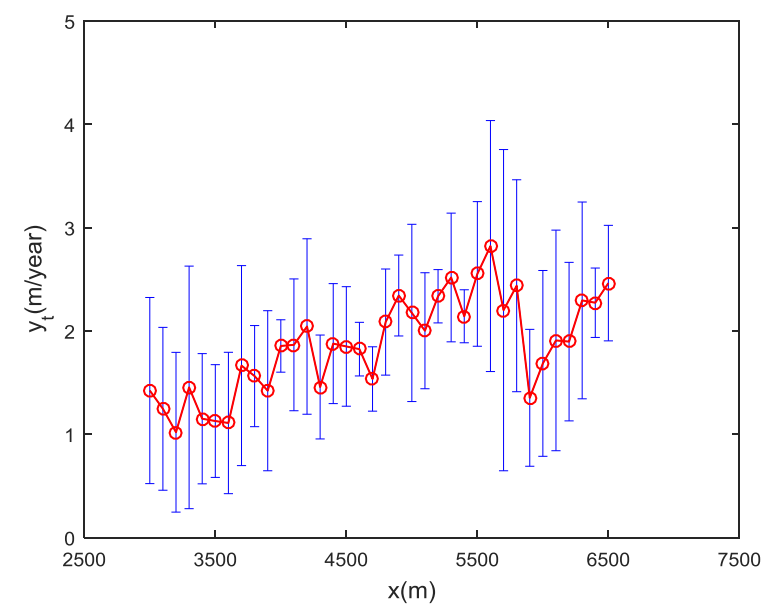

Fig. 16. Four rates and their mean of shoreline change of each section from summer to winter.

Rates of shoreline change of all sections from winter to summer next year are shown in Fig. 17, in which the symbolic definitions follow Fig. 16. Few rates of shoreline change of these sections for each year are positively zero-approaching and most rates are negative. Fig. 17 shows that rates of shoreline change of some sections are widely ranged and more variant than those in Fig. 16. Means of shoreline change rates of these sections for each year vary from -2.59 to -1.11 $\mathrm{m} /$ year with a standard deviation $0.363 \mathrm{~m} /$ year. Averaging all means and standard deviations of shoreline change rates of all sections gives -1.74 and $1.072 \mathrm{~m} /$ year, respectively. The mean of all standard deviations larger for Fig. 17 than that for Fig. 16 indicates the rates of shoreline change from winter to summer next year at different sections vary more than those from summer to winter.

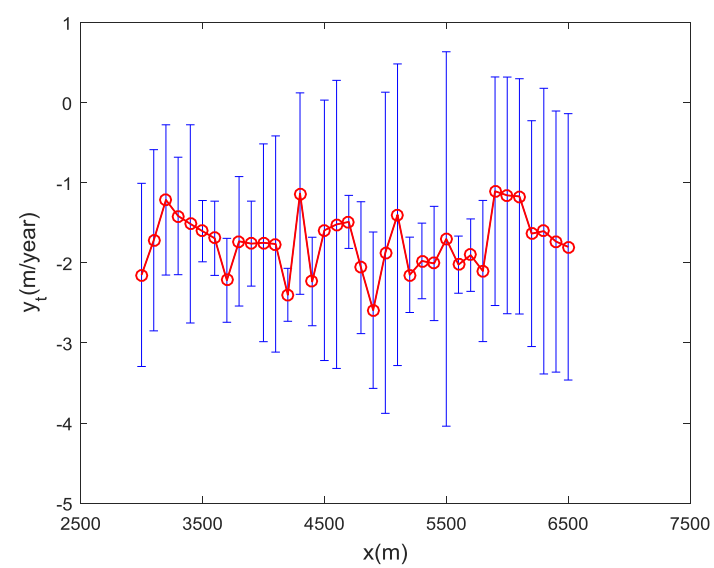

Fig. 17. Four rates and their mean of shoreline change of each section from winter to summer.

\section{CONCLUSION}

Shoreline change can be visibly evaluated by detected waterlines from satellite images in different time. We detect waterlines using an NDWI index of fused multi-spectral satellite images and supervised classification in this study. A correction of an NDWI-based waterline to the shoreline is proposed by triangular geometry when beachface slope and tidal level are available. The method of shifting waterline to shoreline was evaluated applicable for determining shorelines 
from comparisons of obtained shorelines of TGC by in-site measurement in 2004 and 2006

Obtained annual rates of shoreline change of TGC show that the southern beach suffers from erosion and the northern beach is in a state of slight accretion, and the middle beach is in an equilibrium state. Northern shorelines have a seasonal variation, moving landwards during the winter time but oppositely seawards during the summer time. The proposed method can be applied to studying shoreline change in coastal engineering.

\section{REFERENCES}

[1] G. M. Foody, A. M. Muslim, and P. M. Atkinson, "Super-resolution mapping of the waterline from remotely sensed data," International Journal of Remote Sensing, vol. 26, no. 24, pp. 5381-5392, 2005.

[2] A. Niedermeier, D. Hoja, and S. Lehner, "Topography and morphodynamics in the German bright using SAR and optical remote sensing data," Ocean Dynamics, vol. 55, no. 2, pp. 100-109, 2005.

[3] H. Yamano, H. S. Shimazaki, T. Matsunaga, A. Ishoda, C. McClennen, et al., "Evaluation of various satellite sensors for waterline extraction in a coral reef environment: Majuro Atollm Marshall Islands," Geomorphology, vol. 82, no. 3-4, pp. 398-411, 2006.

[4] B. Zhao, H. Guo, Y .Yan, Q. Wang, and B. Li, "A simple waterline approach for tidelands using multi-temporal satellite images: A case study in Yangtze delta," Estuarine, Coastal and Shelf Science, vol. 77, no. 1, pp.134-142, 2008.

[5] J. C. Liou, H. K. Chang, W. W. Chen, and S. R. Liaw, "Beach erosion and preventive countermeasure at Kangnan Coast, Taiwan," Journal of Coastal Research, vol. 25, no. 2, pp.405-406, 2009.

[6] J. E. Pardo-Pascual, J. Almonacid-Caballer, L. A. Ruiz and J. Palomar-Vázquez, "Automatic extraction of shorelines from Landsat $\mathrm{TM}$ and ETM + multi-temporal images with sub pixel precision," Remote Sensing of Environment, vol. 123, pp. 1-11, 2012.

[7] J. H. Ryu, J. S. Won, and K. D. Min, "Waterline extraction from Landsat TM data in a tidal flatA case study in Gomso Bay, Korea," Remote Sensing of Environment, vol. 83, pp. 442-456, 2002.

[8] E. B Boak and I. L. Turner, "Shoreline definition and detection: A review," Journal of Coastal Research, vol. 21, no. 4, pp. 688-703, 2005.

[9] W. W. Chen and H. K. Chang, "Estimation of shoreline position and change from satellite images considering tidal variation," Estuarine, Coastal and Shelf Science, vol. 84, no. 1, pp. 54-60, 2009.

[10] H. K. Chang, W. W. Chen, and J. C. Liou, "Shifting the waterlines of satellite images to the mean water shorelines considering wave runup, setup, and tidal variation," Journal of Applied Remote Sensing, vol. 9, no. 1, 2015. doi: 10.1117 /1.JRS.9.096004.

[11] J. H. Ryu, J. S. Won, and K. D. Min, "Waterline extraction from Landsat TM data in a tidal flat A case study in Gomso Bay, Korea," Remote Sensing of Environment, vol. 83, pp. 442-456, 2002.

[12] A. J. Richardson and C. L. Wiegand, "Distinguishing vegetation from soil background information," Photogrammetric Engineering and Remote Sensing, vol. 43, pp. 1541-1552, 1977.

[13] A. R. Huete, "A soil-adjusted vegetation index (SAVI)," Remote Sensing of Environment, vol. 25, pp. 53-70, 1988.

[14] R. E. Crippen, "Calculating the vegetation index faster," Remote Sensing of Environment, vol. 34, pp. 71-73, 1990.

[15] R. B. Myneni, F. G. Hall, P. J. Sellers, and A. L. Marshak, "The interpretation of spectral vegetation indexes," IEEE Transactions on Geoscience and Remote Sensing, vol. 33, pp. 481-486, 1995.

[16] Y. J. Kaufman and D. Tanre, "Atmospherically resistant vegetation index (ARVI) for EOSMODIS," IEEE Transactions on Geoscience and Remote Sensing, vol. 30, pp. 261-270, 1992.

[17] R. C. Smith, "Remote sensing and depth distribution of ocean Chlorophyll," Marine Ecology, vol. 5, pp. 359-461, 1981.

[18] R. Arnone, M. Babin, A. H. Barnard, E. Boss, J. P. Cannizzaro, and K. L. Carde, "Report 5; Remote sensing of inherent optical properties: fundamentals, tests of algorithms, and applications," Dartmouth, CA: International Ocean-Colour Coordinating Group, 2006.
[19] R. Doerffer and H. Schiller, "The MERIS case 2 water algorithm," International Journal of Remote Sensing, vol. 28, pp. 517-535, 2007.

[20] I. Ioannou, A. Gilerson, G. Gross, F. Moshary, and S. Ahmed, "Neural network approach to retrieve the inherent optical properties of the ocean from observations of MODIS," Applied Optics, vol. 50, pp. 3168-3186, 2011.

[21] S. K. McFeeters, "The use of the normalized difference water index (NDWI) in the delineation of open water features," International Journal of Remote Sensing, vol. 17, no. 7, pp. 1425-1432, 1996.

[22] B.C. Gao, "NDWI- A normalized difference water index for remote sensing of vegetation liquid - water from space," Remote Sensing of Environment, vol. 58, pp. 257-266, 1996.

[23] J. A. Richards, "Remote Sensing Digital Image Analysis - An Introduction," 2nd ed. Springer-Verlag, New York, 1993.

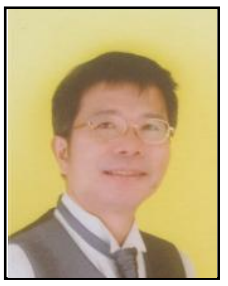

Hsien-Kuo Chang was born in 1960 . He received his $\mathrm{PhD}$ degree in hydraulic and ocean engineering from Cheng Kung University. He is currently a professor of civil engineering in National Chiao Tung University. He specializes in coastal engineering, remote sensing and wavemechanics..

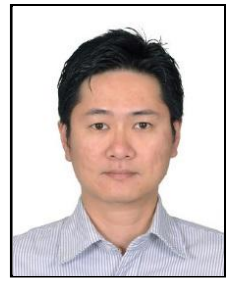

Wei-Wei Chen received his $\mathrm{PhD}$ degree in civil engineering from the National Chiao Tung University. He worked as a postdoctoral fellow at the Department of Civil Engineering in National Chiao Tung University. His current research interests are in image processing and data analysis.

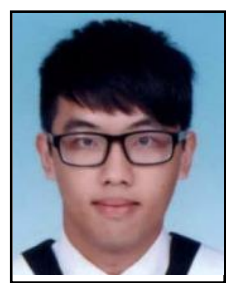

Feng-Chun Tsai was born in 1993. He is a graduate student of civil engineering in National Chiao Tung University, Taiwan. His current research interests in satellite image processing and shoreline evolution.

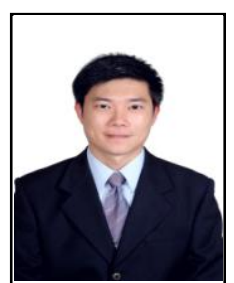

Jin-Cheng Liou was born in 1975. He received his $\mathrm{PhD}$ degree in civil engineering from National Chiao Tung University, Taiwan, in 2005. He worked as a postdoctoral fellow at the Department of Civil Engineering in National Chiao Tung University, Taiwan. His current research interests are in Oceanography numerical model and wave mechanics.

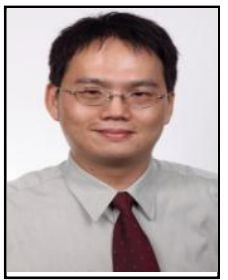

Shao-Gu Kuo was born in 1976. He received his master degree in department of marine environment and engineering from National Sun Yat-Sen University, Taiwan, in 1999. He worked as a senior engineer fellow at the Department of Harbor and Coastal Engineering in CECI Engineering Consultants, Taiwan. His current research interests are in coastal engineering planning and wave mechanics. 